\title{
REPRESENTAÇÃo da INFORMAÇÃo E DO CONHECIMENTO: TESAURO VISUAL NO DOMÍNIO DA ESTATÍSTICA
}

\author{
Olga Bessa Mendes \\ Instituto Nacional de Estatística (Portugal)
}

\section{Introdução}

The great growth of statistical research in our times has made felt the need to record the results in forms less dry, more useful, and able to be explored more rapidly than numbers alone; thus, diverse representations have been imagined, among others my graphic tables and my figurative maps.

The dominant principle which characterizes my graphic tables and my figurative maps is to make immediately appreciable to the eye, as much as possible, the proportions of numeric results.

Paris, 1 December 1861

Charles Joseph Minard ${ }^{1}$

A Comunicação serve-se de imagens e símbolos para representar informação. A primeira sugestão de visualização de informação será a evidência dos mapas, gráficos e símbolos como imagens que representam informação, usados na comunicação para ilustração de discurso.

No contexto da Ciência da informação, e em concreto na biblioteca digital, a pesquisa de informação permite maior especificação mas exige também maior orientação, devido à quantidade e diversidade de informação.

\section{O tesauro visual}

A forma de visualização e representação de informação estatística tem uma atenção especial $^{2}$ e focalizada nos números. E quando o objecto de análise estatística é um conjunto de termos/conceitos, usualmente, o resultado da análise focaliza-se na coocorrência e na frequência de termos.

Considerando o vocabulário controlado uma forma mais eficaz de tratar e pesquisar informação; considerando ainda que, no âmbito da Estatística, para interpretar um gráfico ou um mapa é necessário conhecer e compreender os conceitos estatísticos, propomos a apresentação gráfica das relaçóes entre conceitos/termos substituindo a

${ }^{1}$ MINARD, Charles Joseph - Des tableaux graphiques et des cartes figuratives. Paris, 1862 (trad. Dawn Finley, 2003)

2 Por exemplo, a conferência DD4D-Data design for decisions, organizada pela OCDE em Junho 2009. Disponível em: www.dd4d.net [acedido em 12-06-2009] 
apresentação alfabética de um glossário. Com os contributos da Terminologia e da Engenharia do Conhecimento podemos elaborar um tesauro com a infra-estrutura de um mapa conceptual.

A nossa perspectiva é aliar à utilização de pictogramas, gráficos e mapas temáticos na representação da informação na Estatística, a aplicação do mapa conceptual para complementar o tesauro de informação de especialidade, enquanto instrumento de indexação e de guia de pesquisa na biblioteca digital (Mendes, 2008).

\section{Conclusão}

A formalização da infografia do conteúdo do tesauro, neste domínio, tem por finalidade apresentar uma imagem gráfica dos termos que permita uma melhoria na percepção de informação estatística por parte do utilizador. Do mesmo modo que as operaçóes matemáticas permitem o cálculo dos números, assim as relaçóes entre conceitos permitem desenhar um mapa conceptual (Mendes, 2009). Esta abordagem para a literacia estatística insere-se no quadro amplo do papel social e pedagógico da biblioteca.

\section{Referências bibliográficas}

ALEXANDRINO, Ana (2006) - Gráficos e mapas : representação de informaçáo estatística. Lisboa : Lidel-edições técnicas. ISBN 978-972-757-340-0.

BURKHARD, Remo (2006) - Learning from architects: the difference between knowledge visualization and information visualization. Information Visualization Journal [em linha]. Vol. 5, no 3. [Acedido em 08-05-2008]. Disponível na www: <URL:http://www.palgravejournals.com/ivs/index. html>. ISSN 1473-8716.

MENDES, Olga Bessa (2009) - Estudo de caso: do inquérito ao indicador - o papel da terminologia na informaçáo estatística. [Documento de trabalho] Lisboa: INE.

MENDES, Olga Bessa (2008) - A gestão de informaçáo na biblioteca especializada - as linhas de fronteira da pesquisa de informaçáo. Tese de mestrado. Lisboa : Universidade Nova de Lisboa.

MORGADO, Isabel, ISFAN, Mónica - Documenting variables. Conferência Internacional da Qualidade, Abril 2006. [não publicado].

TRICOT, Christophe (2006) - Cartographie sémantique : des connaissances à la carte [em linha]. Annecy: Université de Savoie. Tese de doutoramento [Acedido em 3-05-2008]. Disponível na www: < http://www.knowledge-mapping.net/>. 